\title{
TWELVE BALANCE EXERCISE LEBIH EFEKTIF DALAM MENURUNKAN RISIKO JATUH DIBANDING OTAGO HOME EXERCISE PADA LANJUT USIA DI BANJAR TAINSIAT, DESA DANGIN PURI KAJA, DENPASAR, BALI
}

\section{Anak Agung Gede Angga Puspa Negara', RA. Tuty Kuswardhani' ${ }^{2}$, Muh. Irfan ${ }^{3}$, I Nyoman Adiputra ${ }^{4}$, Susy Purnawati ${ }^{5}$, I Made Jawi ${ }^{6}$}

${ }^{1}$ Program Studi Magister Fisiologi Keolahragaan, Fakultas Kedokteran, Universitas Udayana, Denpasar ${ }^{2}$ Divisi Geriatri, Departemen Ilmu Penyakit Dalam, Fakultas Kedokteran, Universitas Udayana, RSUP Sanglah, Denpasar

${ }^{3}$ Program Studi Sarjana dan Profesi Fisioterapi, Universitas 'Aisyiyah, Yogyakarta

4,5 Departemen Ilmu Faal, Fakultas Kedokteran, Universitas Udayana, Denpasar

${ }^{6}$ Departemen Farmakologi dan Terapi, Fakultas Kedokteran, Universitas Udayana, Denpasar

\section{email: anggapuspanegara@unud.ac.id}

\begin{abstract}
ABSTRAK
Pendahuluan: Penuaan diiringi oleh penurunan kemampuan fungsional tubuh sehingga meningkatkan risiko terjadinya jatuh pada lansia. Di Indonesia dilaporkan sekitar $17 \%$ bahwa jatuh terjadi, dan di Bali dilaporkan dari keseluruhan lansia yang datang ke Instalasi Gawat Darurat di salah satu rumah sakit di Bali sebesar, 3\% disebabkan oleh karena jatuh. Penilitian ini bertujuan untuk mengetahui apakah twelve balance exercise lebih efektif dalam menurunkan risiko jatuh dibanding otago home exercise pada lansia. Metode: Penelitian ini menggunakan rancangan randomized pre and post test group design. Penelitian ini menggunakan 36 orang yang merupakan anggota komunitas lansia di Banjar Tainsiat Denpasar.. Kelompok 1 diberikan twelve balance exercise, sedangkan Kelompok 2 diberikan otago home exercise. Tiap kelompok diberikan pelatihan selama 6 minggu sebanyak 3 kali dalam seminggu. Risiko jatuh diukur menggunakan berg balance scale (BBS). Hasil: Analisis data menunjukan bahwa terdapat peningkatan nilai BBS secara bermakna pada kedua kelompok. Pada Kelompok 1 didapatkan peningkatan nilai BBS sebesar $(5,06 \pm 1,305)$ dengan p0,000 ( $<<0,05)$ dan pada Kelompok 2 didapatkan peningkatan nilai BBS sebesar $(2,78 \pm 0,647)$ dengan p0,000 ( $<<0,05)$, dan uji perbandingan peningkatan nilai BBS pada kedua kelompok menghasilkan nilai p0,000 ( $<<0,05)$. Simpulan: twelve balance exercise lebih efektif dalam menurunkan risiko jatuh dibanding otago home exercise pada lanjut usia di Banjar Tainsiat, Desa Dangin Puri Kaja, Denpasar, Bali.
\end{abstract}

Kata kunci : twelve balance exercise, otago home exercise, berg balance scale 


\title{
TWELVE BALANCE EXERCISE IS MORE EFFECTIVE IN REDUCING THE RISK OF FALLS COMPARED TO OTAGO HOME EXERCISE IN OLDER PEOPLE AT BANJAR TAINSIAT, DESA DANGIN PURI KAJA, DENPASAR, BALI
}

\begin{abstract}
Introduction: Aging is accompanied by a decrease in the functional ability of the body thereby increasing the risk of falling in the elderly. In Indonesia it was reported that the incidence of falls in the elderly was 17\%, and in Bali it was reported that $3 \%$ of the elderly who visited the Emergency Room at a hospital in Bali were caused by a fall. This study aims to find out whether twelve balance exercise is more effective in reducing the risk of falls compared to otago home exercise in older people. Method: This study using randomized pre and post test group design and using a simple random sampling technique. This study uses 36 people who were members of the elderly community in Banjar Tainsiat Denpasar. Group 1 was given twelve balance exercises, while Group 2 was given otago home exercise. Each group was given treatment for 6 weeks with a frequency of 3 times a week. Fall risk is measured using berg balance scale (BBS). Result: The data analysis showed that there was a significant increase in the value of BBS in both groups. In Group 1 there was an increase in BBS value $(5.06 \pm 1.305)$ with 00.000 $(\mathrm{p}<0.05)$ and in Group 2 the increase in BBS value was $(2.78 \pm 0.647)$ with p0.000 $(\mathrm{p}<0.05)$, and a comparison test of increasing BBS values between the two groups resulted in a value of p0.000 ( $<<0.05$. Conclusion: twelve balance exercise is more effective in reducing the risk of falls compared to otago home exercise in older people Banjar Tainsiat, Desa Dangin Puri Kaja, Denpasar, Bali.
\end{abstract}

Keyword: twelve balance exercise, otago home exercise, berg balance scale

\section{PENDAHULUAN}

Tahun 2015, Indonesia dinyatakan telah berada pada era penduduk menua (aging population) yang dikarenakan oleh penduduk yang berusia lebih dari 60 tahun melebihi angka tujuh persen. ${ }^{1,2}$ Berdasarkan survei yang dilakukan pada tahun 2015, persentase populasi lansia di Indonesia diketahui sebesar 7,65\% dan di Provinsi Bali persentase populasi lansianya sebesar $9,78 \%$ dan menduduki urutan ke-4 populasi lansia terbanyak di Indonesia. ${ }^{2}$

Kejadian jatuh pada lansia banyak dilaporkan diakibatkan oleh berbagai faktor internal maupun eksternal. ${ }^{3} \mathrm{Di}$ beberapa negara diluar Indonesia, kejadian jatuh pada lansia dilaporkan terjadi sebesar $28 \%{ }^{4}$ Sementara di Indonesia, kejadian jatuh pada lansia dilaporkan sebesar 17\%, sedangkan di Bali sendiri dilaporkan lansia yang datang ke Instalasi Gawat Darurat yang disebabkan oleh karena jatuh memunculkan persentase sebesar $3 \% .^{5,6}$

Kejadian jatuh mengakibatkan bertambahnya angka kesakitan dan juga menyebabkan bertambahnya angka kematian lansia di seluruh dunia. Sebuah studi yang dilakukan memperoleh hasil dimana 30\% lansia yang berusia di atas 65 tahun dilaporkan mengalami jatuh di setiap tahunnya, dan setengahnya mengalami jatuh berulang. ${ }^{7}$ Studi lain juga menyebutkan bahwa lansia yang pernah mengalami jatuh cenderung sekitar 30-73\% akan mengalami jatuh berulang. ${ }^{8}$

Kejadian jatuh sangat erat kaitannya dengan keseimbangan, dimana sebuah studi menyatakan bahwa adanya hubungan antara kejadian jatuh dengan keseimbangan dan dan pada penelitian tersebut diperoleh hasil sebesar $28,3 \%$ responden mengalami risiko jatuh tinggi, $46,7 \%$ responden mengalami risiko jatuh sedang, dan $25 \%$ responden 
mengalami risiko jatuh rendah. Maka dari itu, focus utama untuk menangani permasalahan jatuh pada lansia adalah dengan memperbaiki dan menjaga keseimbangan pada lansia itu sendiri. ${ }^{9}$

Upaya untuk mengatasi masalah keseimbangan pada lansia adalah dengan salah satunya dengan menerapkan program latihan keseimbangan yang efektif. Berbagai macam latihan keseimbangan, telah terbukti efektif dapat memperbaiki keseimbangan lansia sehingga dapat menurunkan risiko jatuh pada lansia, diantaranya adalah pelatihan twelve balance exercise dan otago home exercise.

Twelve balance exercise merupakan sebuah program latihan dengan metode latihan menggunakan 12 jenis gerakan, sedangkan otago home exercise dapat dikatakan mirip dengan twelve balance exercise, menggunakan beberapa jenis gerakan untuk melatih keseimbangan, namun dalam otago home exercise, latihan dilakukan dengan cara mengkombinasikan latihan penguatan (strengthening), latihan keseimbangan (balancing) dan program jalan yang berfokus pada penggunaan otototot ekstremitas dan postural.

\section{BAHAN DAN METODE}

Penelitian diawali dengan penentuan populasi target yang dilanjutkan dengan pengukuran risiko jatuh pada populasi untuk mendapatkan subjek sesuai dengan inklusi, kemudian dilakukan pengambilan sampel dengan teknik simple random sampling untuk mendapatkan sampel sesuai dengan perhitungan jumlah sampel dan Teknik random alokasi untuk membagi sampel menjadi 2 kelompok berbeda, dimana kelompok 1 diberikan twelve balance exercise dan kelompok 2 diberikan otago home exercise. Dilanjutkan dengan pelatihan selama 6 minggu dan kembali dilakukan pengukuran keseimbangan dinamis setelah pelatihan. Risiko jatuh diukur menggunakan berg balance scale.

Data yang telah diperoleh dianalisis dengan menggunakan uji statistik deskriptif pada usia, nilai BBS sebelum pelatihan, dan nilai MMSE.

\section{HASIL}

Karakteristik sampel penelitian yang meliputi usia, nilai BBS, dan nilai MMSE pada Kelompok 1 dan 2 dapat dilihat pada Tabel 1.

Tabel 1. Karakteristik Sampel Penelitian

\begin{tabular}{ccccccc}
\hline \multirow{2}{*}{ Karakteristik } & \multicolumn{3}{c}{$\begin{array}{c}\text { Kelompok 1 } \\
\text { (TBE) }\end{array}$} & \multicolumn{3}{c}{$\begin{array}{c}\text { Kelompok 2 } \\
\text { (OHE) }\end{array}$} \\
\cline { 2 - 7 } & $\mathrm{n}$ & Rerata & SB & $\mathrm{n}$ & Rerata & SB \\
Usia (th) & 18 & 68,22 & 4,760 & 18 & 67,44 & 4,540 \\
Nilai BBS Sebelum Pelatihan & 18 & 35,44 & 2,064 & 18 & 35,22 & 3,001 \\
Nilai MMSE & 18 & 27,94 & 1,056 & 18 & 28,00 & 1,029 \\
\hline
\end{tabular}

Tabel 1. menunjukkan jumlah subjek penelitian pada tiap kelompok berjumlah 18 orang. Subjek penelitian pada Kelompok 1 (TBE) memiliki rerata usia $(68,22 \pm 4,760)$ tahun, rerata nilai BBS sebelum pelatihan sebebsar $(35,44 \pm 2,064)$, serta rerata nilai MMSE sebesar $(27,94 \pm 1,056)$, dan subjek pada Kelompok 2 (OHE) memiliki rerata usia $(67,44 \pm 4,540)$ tahun, rerata nilai BBS sebelum pelatihan $(35,22 \pm 3,001)$, serta rerata nilai MMSE sebesar $(28,00 \pm 1,029)$.

Karakteristik sampel penelitian berdasarkan jenis kelamin dapat dilihat pada Tabel 2. 
Tabel 2. Karakteristik Sampel Penelitian pada Kelompok 1 dan 2 berdasarkan jenis kelamin

\begin{tabular}{ccccc}
\hline Jeni Kelamin & \multicolumn{2}{c}{ Kelompok 1 (TBE) } & \multicolumn{2}{c}{ Kelompok 2 (OHE) } \\
\cline { 2 - 5 } & $\mathbf{n}$ & Persentase $\mathbf{( \% )}$ & $\mathbf{n}$ & Persentase \%) \\
\hline Laki-laki & 7 & 38.89 & 7 & 38,89 \\
\hline Perempuan & 11 & 61,11 & 11 & 61,11 \\
\hline Total & 18 & 100 & 18 & 100
\end{tabular}

Tabel 2. menunjukkan bahwa pada Kelompok 1 (TBE) dan Kelompok 2 (OHE) subjek yang berjenis kelamin laki-laki masing-masing kelompok sebanyak 7 orang
$(38,89 \%)$ dan perempuan masing-masing kelompok sebanyak 11 orang $(61,11 \%)$.

Hasil uji normalitas dan uji homogenitas pada kelompok 1 dan 2 dapat dilihat pada Tabel 2.

Tabel 3. Uji Normalitas dan Uji Homogenitas

\begin{tabular}{cccc}
\hline \multirow{2}{*}{ Variabel } & \multicolumn{2}{c}{$\begin{array}{c}\text { p. Normalitas } \\
\text { (Shapiro-Wilk Test) }\end{array}$} & \multirow{2}{*}{$\begin{array}{c}\text { p. Homogenitas } \\
\text { (Levene's Test) }\end{array}$} \\
\cline { 2 - 3 } & $\begin{array}{c}\text { Kelompok 1 } \\
\text { (TBE) }\end{array}$ & $\begin{array}{c}\text { Kelompok 2 } \\
\text { (OHE) }\end{array}$ & \\
\hline Nilai BBS Sebelum Pelatihan & 0,125 & 0,234 & 0,056 \\
Nilai BBS Sesudah Pelatihan & 0,401 & 0,643 & 0,100 \\
\hline
\end{tabular}

Tabel 3. menunjukkan hasil uji normalitas pada Kelompok 1 (TBE), nilai BBS sebelum pelatihan didapatkan nilai $\mathrm{p}=0,125 \quad(\mathrm{p}>0,05)$, dan sesudah pelatihan didapatkan nilai $\mathrm{p}=0,401 \quad(\mathrm{p}>0,05)$ yang berarti data dari nilai BBS pada Kelompok 1 (TBE) adalah berdistribusi normal dan Kelompok 2 (OHE), pada nilai BBS sebelum didapatkan nilai $p=0,234(p>0,05)$, dan sesudah pelatihan didapatkan nilai $\mathrm{p}=0,643(\mathrm{p}>0,05)$ yang berarti nilai BBS pada Kelompok 2 (OHE) adalah berdistribusi normal.

Hasil uji homogenitas pada Tabel 3. menunjukkan bahwa nilai BBS pada kedua kelompok bersifat homogen karena sebelum pelatihan didapatkan nilai $\mathrm{p}=0,056(\mathrm{p}>0,05)$ dan sesudah pelatihan didapatkan nilai $\mathrm{p}=0,100(\mathrm{p}>0,05)$ yang berarti bahwa data penelitian pada kedua kelompok memiliki varian atau karakteristik yang sama.

Uji hipotesis Kelompok 1 (TBE) dapat dilihat pada Tabel 4.

Tabel 4. Peningkatan nilai BBS pada Kelompok 1 (TBE)

\begin{tabular}{ccccccc}
\hline Perlakuan & Rerata & SB & Selisih & SB & p & \% \\
\hline Nilai BBS Sebelum Pelatihan & 35,44 & 2,064 & \multirow{2}{*}{5,06} & \multirow{2}{*}{1,305} & \multirow{2}{*}{0,000} & \multirow{2}{*}{14,25} \\
Nilai BBS Sesudah Pelatihan & 40,50 & 2,121 & & & & \\
\hline
\end{tabular}

Tabel 4. menunjukkan nilai BBS sebelum dan sesudah perlakuan pada Kelompok 1 (TBE), didapatkan nilai $\mathrm{p}=0,000(\mathrm{p}<0,05)$
Uji hipotesis Kelompok 2 (OHE) dapat dilihat pada Tabel 5.

Tabel 5. Peningkatan nilai BBS pada Kelompok 2 (OHE)

\begin{tabular}{ccccccc}
\hline Perlakuan & Rerata & SB & Selisih & SB & p & \% \\
\hline Nilai BBS Sebelum Pelatihan & 35,22 & 3,001 & \multirow{2}{*}{2,78} & \multirow{2}{*}{0,647} & \multirow{2}{*}{0,000} & \multirow{2}{*}{7,89} \\
Nilai BBS Sesudah Pelatihan & 38,00 & 2,990 & & & & \\
\hline
\end{tabular}


Tabel 5. menunjukkan nilai BBS sebelum dan sesudah pelatihan pada Kelompok 2 (OHE), didapatkan nilai $\mathrm{p}=0,000(\mathrm{p}<0,05)$
Uji perbedaan peningkatan nilai BBS pada kedua kelompok dapat dilihat pada Tabel 6.

Tabel 6. Perbandingan Peningkatan nilai BBS pada Kelompok 1 (TBE) dan Kelompok 2 (OHE)

\begin{tabular}{cccccc}
\hline \multirow{2}{*}{ Perlakuan } & \multicolumn{2}{c}{ Kelompok 1 (TBE) } & \multicolumn{2}{c}{ Kelompok 2 (OHE) } & \multirow{2}{*}{$\mathrm{p}$} \\
\cline { 2 - 5 } & Rerata & SB & Rerata & SB & \\
\hline Nilai BBS Sebelum Pelatihan & 35,44 & 2,064 & 35,22 & 3,001 & 0,797 \\
Nilai BBS Sesudah Pelatihan & 40,50 & 2,121 & 38,00 & 2,990 & 0,007 \\
Selisih Nilai BBS & 5,06 & 1,305 & 2,78 & 0,647 & 0,000 \\
\hline
\end{tabular}

Tabel 6. menampilkan nilai BBS sesudah pelatihan diperoleh nilai $p=0,000(p<0,05)$.

\section{DISKUSI}

\section{Karakteristik Sampel Penelitian}

Penelitian ini menggunakan sampel lansia pada kisaran usia 60-74 tahun, karena pada rentangan usia tersebut terjadi penurunan fungsi tubuh dan terjadi peningkatan risiko terjadinya gangguan pada tubuh, salah satunya meningkatnya risiko jatuh. Usia di atas 65 tahun tercatat mengalami jatuh dengan prevalensi mencapai $30 \%$ pada tiap tahunnya. Lansia dengan rentang usia 60-74 tahun ditemukan memiliki risiko jatuh sebesar 4,5\%, pada retang usia 75-90 tahun didaptkan memiliki risiko jatuh sebesar 7,5\%, dimana sebesar $31,3 \%$ risiko jatuh terjadi pada perempuan dan $6 \%$ pada laki-laki. ${ }^{10}$ Hal tersebut menunjukkan bahwa semakin bertambahnya usia seseorang akan diikuti dengan terjadinya penurunan fungsi tubuh, salah satunya mempengaruhi fungsi keseimbangan sehingga menyebabkan meningkatnya risiko jatuh khususnya pada lansia. Pada usia tersebut mulai terjadi penurunan kontrol postural dan sistem integrasi keseimbangan yang dapat mempengaruhi keseimbangan pada lansia tersebut, sehingga risiko jatuh oleh karena gangguan keseimbanganpun berpotensi besar untuk meningkat. ${ }^{11}$

Karakteristik sampel penelitian yang meliputi: usia dan nilai BBS sebelum pelatihan pada kedua kelompok tersebut tidak memiliki perbedaa yang bermakna
Dari hasil analisis data didapatkan semua subjek penelitian memliki nilai MMSE yang masuk dalam kategori normal. Pemeriksaan MMSE penting dilakukan untuk lebih awal mengetahui nilai kognitif dari subjek dan dalam penelitian nilai MMSE subjek yang diharapkan adalah yang masuk dalam kategori normal, karena dalam pelaksanaan pelatihan ada kedua kelompok dibutuhkan kemampuan kognitif subjek yang baik untuk mengingat atau mengafal urutan pelatihan yang diberikan. Apabila setelah pelatihan selama enam minggu terdapat perbedaan hasil dari kedua kelompok, maka dapat dipastikan hal tersebut diakibatkan oleh dari latihan yang diberikan pada masing-masing kelompok.

\section{Twelve Balance Exercise efektif dalam Menurunkan Risiko Jatuh pada Lanjut Usia melalui Peningkatan Nilai BBS}

Gerakan pada twelve balance exercise dinyatakan mampu mengaktifkan gerakan volunteer pada tubuh, respon postural secara otomatis dari tubuh, serta gerak refleks dari tubuh untuk mempertahankan posisi tubuh. Rangkaian gerakan pada tweleve balance exercise juga dinyatakan mampu meningkatkan limit of stability, meningkatkan sistem motorik, meningkatkan integrasi sensoris termasuk ketiga sistem yang saling berkerja sinergis yaitu sistem visual, vestibular dan somatosensoris, meningkatkan stabilitas statis dan dinamis, serta meningkatkan kontrol postural. ${ }^{12}$ 
Gerakan tandem stance, body circles, dan single limb stance diketahui dapat memberikan adaptasi neural pada sistem saraf berupa spatial summation dan temporal summation. Adaptasi yang terjadi akan memberi respon berupa peningkatan jumlah unit motorik yang diikuti oleh peningkatan kekuatan otot. ${ }^{13}$ Selain uraian diatas gerakan tandem stance, single limb stance, dan body circles juga diketahui dapat menyebabkan peningkatan kekuatan pada otot yang bertugas menjaga stabilitas tubuh dalam mengantisipasi terjadinya perubahan pada pusat gravitasi tubuh, sehingga keseimbangan tubuh dapat tetap terjaga. ${ }^{14}$

Gerakan single limb stance with arm, clock reach, dan balancing wand diketahui akan menyebabkan terjadinya respon postural otomatis pada tubuh, hal tersebut disebabkan oleh karena adanya rangsangan berupa percepatan linier yang diterima oleh makula utrikulus. Rasangan tersebut dikirim melalui vestibularis nerve menuju ke nuklei vestibular yang berikutnya akan di olah di brain stem. Sinyal yang diterima di brain stem akan diteruskan ke otot-otot antigravitasi melalui vestibulospinalis medialis dan lateralis tract. Hal terssebut akan direspon tubuh dengan munculnya feedback berupa kemampuan proteksi dan koreksi selama terjadi perubahan landasan atau arah pergerakan, sehingga keseimbangan terjaga dan risiko jatuh dapat ditekan. ${ }^{15}$

Gerakan knee marching, grapevine, dan heel to toe diketahui dapat memicu pengaktifan otot-otot yang memiliki peran dalam kontrol gerakan dinamik seseorang, seperti gerakan melangkah dan sebagainya. Penjelasan lain juga menyatakan bahwa gerakan knee marching, grapevine, dan heel to toe akan meningkatkan kekuatan otot-otot yang berperan dalam melakukan gait and locomotion sehingga dapat menyebabkan terjadi stabilisasi dinamik saat tubuh melakukan pergerakan. Gerakan ini juga berperan dalam meningkatkan panjang langkah, mengurangi lebar langkah, serta waktu tempuh. ${ }^{8}$
Gerakan eye tracking, stepping exercise, dan dynamic walking akan mengaktifkan respon postural otomatis yang berikutnya akan mengaktifkan kinerja sistem integrasi sensoris dan sistem feedforward. Gerakan eye tracking berperan pada sistem visual yang memegang peranan penting dalam sistem sensoris. Adanya peningkatan pada sistem visual dapat meningkatkan kontrol gerakan. Pada saat melakuakan gerakan eye tracking sistem visual akan beradaptasi terhadap perubahan yang terjadi di lingkungan dan akan memberikan informasi ke otak yang akan bekerja sinergis dalam mempertahankan keseimbangan. ${ }^{15}$

Penurunan risiko jatuh pada pelatihan ini tercapai oleh karena adanya: 1) peningkatan kekuatan pada otot postural dimana hal tersebut akan memicu limit of stability recovery, 2) tercapainya respon otomatis postural melalui mekanisme movement feedback yang meningkatkan kemampuan korektif dan protektif, 3) peningkatan kontrol pada gerakan dinamik, 4) aktivasi sistem feedforward, dan 5) tercapainya sensory integrity berupa sensory strategies dan sensory re-weighting. ${ }^{12}$

\section{Otago Home Exercise Efektif dalam Menurunkan Risiko Jatuh pada Lanjut Usia melalui Peningkatan Nilai BBS}

Penurunan risiko jatuh dengan menggunakan metode otago home exercise utamanya memberikan perbaikan berupa penguatan otot khususnya otot-otot ekstremitas bawah. Perbaikan tersebut didapatkan dengan melakukan 12 latihan keseimbangan yang dibagi menjadi 4 level. Pada level pertama, hamper keseluruhan gerakan dilakukan menggunakan bantuan tangan. $^{16}$

Pelatihan untuk meningkatan kekuatan untuk meningkatkan kekuatan dari abduktor hip, fleksor knee, ekstensor knee, dan berat badan yang digunakan untuk meningkatkan kekuatan dari otot - otot plantarfleksi dan dorsofleksi ankle. Latihan pada lansia usia 60 tahun ke atas dengan beban yang ditambah secara progresif 
diketahui dapat meningkatkan kekuatan otot dari lansia tersebut. ${ }^{7}$ Gerakan knee bends, tandem stance, one leg stand, sit to stand akan menyebabkan terjadinya respon dari tubuh untuk melakukan gerakan volunter. Saat gerakan tersebut dilakukan tubuh akan memberi respon berupa sinyal yang dikirimkan melalui mekanoreseptor yang kemudian diteruskan ke girus postcentralis pada korteks serebri, dalam waktu yang singkat sinyal yang diterima akan diolah yang kemudian menghasilkan sinyal motorik pada serabut pyramidal dan berakhir pada neuron motorik sisi anterior. Hasil potensial aksi tersebut yang diterima oleh neuron motorik anterior, akan disampai ke akson terminal hingga menghasilkan potensial end plate dan menyebabkan terjadinya kontraksi otot. ${ }^{13}$

Kemampuan berjalan secara mandiri berpengaruh pada produktivitas lansia dan merupakan cara efektif untuk berpindah tempat. Pada lansia umumnya terjadi penurunan kapasitas aerobik, fleksibilitas sendi, kekuatan otot dan kepadatan tulang, sehingga terjadinya penurunan pada kecepatan jalan dan panjang langkah, selain itu fase berdiri dengan tumpuan pada kedua tungkai juga semakin lama dan fase heel off berkurang yang menyebabkan gangguan pada pola jalan. $^{7}$

Gerakan backward walking, walking and turning around, heel walking, stair walking, tandem walk, sideways walking, toe walking, dan heel toe walking backwards akan menyebabkan terjadinya respon postural otomatis pada tubuh, hal tersebut disebabkan oleh rangsangan berupa percepatan linier yang diterima oleh makula utrikulus. Rasangan tersebut dikirim melalui vestibularis nerve ke vestibular nuclei yang berikutnya akan di olah di brain stem. Brain stem akan mengirimkan sinyal yang kuat ke melalui vestibulospinalis medialis dan lateralis tract untuk mengaktifkan otot-otot antigravitasi. Hal terssebut akan direspon tubuh dengan munculnya feedback berupa kemampuan proteksi dan koreksi selama terjadi perubahan landasan atau arah pergerakan, sehingga keseimbangan terjaga dan risiko jatuh dapat ditekan. ${ }^{15}$

Gerakan backward walk, heel to toe walking, walking and turning around, dan stair walking berfokus pada perbaikan kecepatan saat melangkah, jarak yang ditempuh, perubahan arah, peningkatan tonus dan kekuatan otot selama latihan berjalan. Pada latihan stair walking fokus latihan adalah pengontrolan keseimbangan, ekstensi dan kontraksi dari otot ekstremitas bawah dan dorsofleksi ankle untuk memindahkan pusat gravitasi tubuh untuk mengontrol afferen, efferen dan kontraksi dari otot - otot pada ekstremitas bawah. Hasil dari latihan tersebut koordinasi tubuh menjadi lebih baik dan tubuh dapat belajar untuk memindahkan pusat gravitasi tubuh selama melangkah, sehingga akan terjadi peningkatan dari kecepatan berjalan dan panjang langkah. ${ }^{8}$

\section{Twelve Balance Exercise Lebih Efektif dalam Menurunkan Risiko Jatuh pada Lanjut Usia dibanding Otago Home Exercise}

Pelatihan eye tracking, stepping exercise, dan dynamic walking pada twelve balance exercise merupakan kelebihan yang menyebabkan twelve balance exercise dapat lebih efektif menurunkan risiko jautuh pada lansia melalui peningkatan nilai BBS. Hal tersebut disebabkan oleh adanya eye tracking, stepping exercise, dan dynamic walking yang akan memicu terciptanya integrasi sensoris yang baik dan psistem feedforward melalui respon postural otomatis, dimana efek ini tidak didapatkan pada otago home exercise.

Gerakan eye tracking berperan pada sistem visual yang memegang peranan penting dalam sistem sensoris. Adanya peningkatan pada sistem visual dapat meningkatkan kontrol gerakan. Pada saat melakuakan gerakan eye tracking sistem visual akan beradaptasi terhadap perubahan yang terjadi di lingkungan dan akan memberikan informasi ke otak yang akan bekerja sinergis dalam mempertahankan keseimbangan. ${ }^{15}$ 
Gerakan dynamic walking akan memberikan rasangan kanalis semisirkularis, dimana dalam kanalis semisirkularis terdapat cairan yang akan mengalir dari kanalis menuju ampula. Hal tersebut memicu terjadinya depolarisasi pada sel-sel rambut dan rasangan tersebut dikirim melalui vestibularis nerve yang akn menyampaikan informasi mengenai perubahan posisi kepala serta kecepatan perubahan posisi kepala. ${ }^{17}$ Gerakan dynamic walking menyampaikan informasi tambahan pada somatosensoris yang memicu terciptanya integrasi sensoris terkait keseimbangan yakni: integrasi pada sistem visual, vestibular, dan somatosensoris. Saat melakukan gerakan dynamic walking dengan tantangan maka akan terjadi stimulasi pada optimalisasi fungsi sensori integrase serta optimalisasi pada sensory reweighting, hal tersebut akan menyebabkan terjadinya adaptasi pada sistem sensoris yang membagi informasi tersebut secara merarata serta dapat mengurangi ketergantungan masukan somatosensori sehingga tercipta kinerja otot yang lebih efisien. ${ }^{14}$

Gerakan Stepping exercise akan pengaktifan fungsi dari vestibuloserebelum yang memiliki peran dalam menghitung kecepatan arah dan memprediksi gerakan yang akan datang selama beberapa milidetik.

Pada twelve balance exercise, tercapai integrasi sensoris didapatkan melalui gerakan eye tracking, stepping exercise, dan dynamic walking, dimana gerakan stepping exercise dan eye tracking diketahui akan mengaktifkan vestibuloocular reflex. ${ }^{11}$ Gerakan stepping exercise juga memberikan tambahan informasi pada somatosensoris tubuh, sehingga dapat mendukung tercapainya konsep integrasi sensoris untuk menjaga keseimbangan tubuh dan menurunkan risiko terjaidnya jatuh. Gerakan dynamic walking menyebabkan timbulnya eksitasi di apparatus vestibular dalam kanalis semisirkularis. ${ }^{8,17}$

\section{SIMPULAN}

Berdasarkan hasil analisis dan pembahasan yang telah dilakukan, maka disimpulkan bahwa: twelve balance exercise lebih efektif dalam menurunkan risiko jatuh dibanding otago home exercise pada lanjut usia di Banjar Tainsiat, Desa Dangin Puri Kaja, Denpasar, Bali.

\section{DAFTAR PUSTAKA}

1. PP, 2004. Peraturan Pemerintah Republik Indonesia nomor 43 tahun 2004 tentang Pelaksanaan Upaya Peningkatan Kesejahteraan Sosial Lanjut Usia. Indonesia : Pemerintah Republik Indonesia.

2. Kemenkes, 2017. Kementerian Kesehatan Republik Indonesia: Analisis Lansia di Indonesia, Jakarta Selatan: Pusat data dan Informasi.

3. Meiner \& Lueckenotte, 2006. Gerontologic Nursing. 3rd penyunt. St. Louis: Mosby Elsevier.

4. Halil, M., Ulger, Z., Cankurtaran, M., Shorbagi, A., Yavuz, BB., Dede,. D, Ozkayar, N., Ariogul, S., 2006. Falls and the elderly: Is there any difference in the developing world?: A crosssectional study from Turkey. Archives of Gerontology and Geriatrics, 43(3), pp. 351-359.

5. Ariawan, Kuswardhani, Astika \& Aryana, 2011. Hubungan antara activities specific balance confidence scale dengan umur dan falls pada lansia di poliklinik geriatric RSUP Sanglah Denpasar. Jurnal Penyakit Dalam, 12(1), pp. 34-37.

6. Suyasa, Agustini \& Adiana, 2014. Alasan kunjungan lanjut usia ke Instalasi Gawat Darurat, Denpasar: Stikes Bali.

7. Mahendra, W., 2016. Pemberian Otago Home Exercise Programme Lebik Baik dalam Mengurangi Risiko Jatuh daripada Balance Stratgei Exercise 
pada Lansia di Tabanan. Denpasar: Universitas Udayana.

8. Nugraha, M. H. S., Wahyuni, N. \& Muliarta, I. M., 2016. Pelatihan 12 Balance Exercise Lebih Meningkatkan Keseimbangan Dinamis daripada Balance Strategy Exercise pada Lansia di Banjar Bumi Shanti, Desa Dauh Puri Kelod, Kecamatan Denpasar Barat. Majalah Ilmiah Fisioterapi Indonesia, 4(1).

9. Arianda, R., 2014. Hubungan antara Keseimbangan Tubuh dengan Riwayat Jatuh pada Lanjut Usia [Skripsi]. Surakarta: Universitas Muhammadiyah Surakarta.

10. Utami, F. Y., 2015. Hubungan Indeks Massa Tubuh Dan Kecepatan Jalan Dengan Risiko Jatuh Pada Lanjut Usia. Dalam: Surakarta: Program Studi S1 Fisioterapi Fakultas Ilmu Kesehatan Universitas Muhammadiyah Surakarta.

11. Guccione, A. A., Wong, R. A. \& Avers, D., 2012. Geriatric Physical Therapy. 3rd penyunt. Missouri: Elsevier Mosby.

12. Wolf, B., Feys, H., De Weerdt, van der Meer, J., Noom, M., Aufdemkampe, G., Noom, M., 2001. Effect of A Physical Therapeutic Intervention for Balance Problems in The Elderly: A SingleBlind, Randomized, Controlled Multicentre Trial. Netherlands: Department of Physical Therapy, Stichting Zorgcentrum Texel.

13. Squire, L. Spitzer, L., Berg, D., Bloom, F.E., Ghosh, A., 2008. Fundamental Neuroscience. USA: Elsevier.

14. Sibley, K. Beauchamp, M.K., Van Ooteghem, K., Straus, S.E., Jaglal, S.B., 2015. Using the System Framework for Postural Control to Analyze the Components of Balance Evaluated in Standardized Balance Measures. A Scoping Review American Congress of Rehabilitation Medicine, Volume 96, pp. 122-132.

15. Guyton, A. \& Hall, J., 2008. Fisiologi Kedokteran. Singapore: Elsevier.

16. Slijper, H. \& Latash, M., 2000. The effects of instability and additional hand support on anticipatory postural adjustments in leg, trunk, and arm muscles during standing. Experimental Brain Research , 135(1), pp. 81-93.

17. Peterka, R., 2002. Sensorimotor integration in human postural control. J Neurophys, Issue 88, pp. 109-118. 